\title{
Postconcussion syndrome: demographics and predictors in 221 patients
}

\author{
Charles H. Tator, MD, PhD, FRCSC,,2 Hannah S. Davis, BSCH,1 Paul A. Dufort, PhD, ${ }^{1}$ \\ Maria Carmella Tartaglia, MD, FRCPC, ${ }^{1,3}$ Karen D. Davis, PhD, ${ }^{1-3}$ Ahmed Ebraheem, MBChB, PhD, ${ }^{1}$ \\ and Carmen Hiploylee, MSc ${ }^{1}$
}

${ }^{1}$ Canadian Concussion Centre, Toronto Western Hospital; and Divisions of ${ }^{2}$ Neurosurgery and ${ }^{3}$ Neurology, University of Toronto and Toronto Western Hospital, Toronto, Ontario, Canada

OBJECTIVE The objective of this study was to determine the demographics and predictors of postconcussion syndrome (PCS) in a large series of patients using a novel definition of PCS.

METHODS The authors conducted a retrospective cohort study of 284 consecutive concussed patients, 221 of whom had PCS on the basis of at least 3 symptoms persisting at least 1 month. This definition of PCS was uniformly employed and is unique in accepting an expanded list of symptoms, in shortening the postconcussion interval to 1 month from 3 months, and in excluding those with focal injuries such as hemorrhages and contusions.

RESULTS The 221 cases showed considerable heterogeneity in clinical features of PCS. They averaged 3.3 concussions, with a range of 0 to 12 or more concussions, and $62.4 \%$ occurred during sports and recreation. The median duration of PCS was 7 months at the time of examination, with $11.8 \%$ lasting more than 2 years, and $23.1 \%$ with PCS had only 1 concussion. The average patient age was 27 years (range 10-74 years). The average number of persistent symptoms was $8.1 ; 26.2 \%$ had a previous psychiatric condition, attention-deficit disorder/attention-deficit hyperactivity disorder, a learning disability, or previous migraine headaches. The prevalence of arachnoid cysts and Chiari malformation in PCS exceeded the general population. Additionally, involvement in litigation, presence of extracranial injuries, amnesia and/or loss of consciousness, and female sex were predictive of reporting a high number of symptoms. A prior history of psychiatric conditions or migraines, cause of injury, number of previous concussions, and age did not significantly predict symptom number. Only the number of symptoms reported predicted the duration of PCS. To predict the number of symptoms for those who fulfilled PCS criteria according to the International Classification of Diseases, 10th Revision (ICD-10), and the Diagnostic and Statistical Manual of Mental Disorders, 4th Edition (DSM-IV), the number of previous concussions was significant.

CONCLUSIONS PCS is commonly associated with multiple concussions, but $23.1 \%$ in the present series occurred after only 1 concussion. Most patients with PCS had multiple symptoms persisting for months or years. The median duration of PCS was 7 months, with a range up to 26 years. In only $11.3 \%$, the PCS had ended at the time of consultation. Not all predictors commonly cited in the literature align with the findings in this study. This is likely due to differences in the definitions of PCS used in research. These results suggest that the use of ICD-10 and DSM-IV to diagnose PCS may be biased toward those who are vulnerable to concussions or with more severe forms of PCS. It is thus important to redefine PCS based on evidence-based medicine.

http://thejns.org/doi/abs/10.3171/2015.6.JNS15664

KEY WORDS postconcussion syndrome; concussion; traumatic brain injury; chronic traumatic encephalopathy

ABBREVIATIONS $A D D=$ attention-deficit disorder; $A D H D=$ attention-deficit hyperactivity disorder; $C T E$ = chronic traumatic encephalopathy; $D S M-I V=$ Diagnostic and Statistical Manual of Mental Disorders, 4th Edition; GCS = Glasgow Coma Scale; ICD-10 = International Classification of Diseases, 10th Revision; LOC = Ioss of consciousness; PCS = postconcussion syndrome; PTSD = posttraumatic stress disorder; $T B I=$ traumatic brain injury.

ACCOMPANYING EDITORIAL See pp 1204-1205. DOI: 10.3171/2015.7.JNS151335.

SUBMITTED April 1, 2015. ACCEPTED June 9, 2015.

INCLUDE WHEN CITING Published online February 26, 2016; DOI: 10.3171/2015.6.JNS15664. 
$\mathrm{M}$ OST individuals recover from a concussion within 7-10 days, but some do not recover for months or years after injury, and some never recover. Individuals who do not recover within the usual time are said to have postconcussion syndrome (PCS). Studies of PCS have reported major differences in the incidence of this syndrome, ranging from less than $5 \%{ }^{17}$ to $58 \%,{ }^{6}$ but the most commonly reported incidence is $10 \%-15 \%$ of concussions. ${ }^{19,33,34}$ One major reason for this large range is the lack of agreement about the definition of PCS. The International Classification of Diseases, 10th Revision (ICD-10) requires 3 symptoms or more from a restricted list of symptoms including headache, dizziness, fatigue, irritability, insomnia, concentration difficulty, memory difficulty, and reduced tolerance to stress, emotional excitement, or alcohol ${ }^{42}$ In contrast, the Diagnostic and Statistical Manual of Mental Disorders, 4th Edition (DSMIV) requires 3 or more symptoms from a different list, including fatigue, sleep disturbance, headache, dizziness, irritability, affective disturbance, personality change, and apathy, and requires symptoms to last 3 or more months following injury. Also, DSM-IV requires the presence of cognitive deficits in attention and/or memory and a significant decline in social and/or occupational functioning. ${ }^{2}$ In DSM-V, PCS was replaced by "Major or Mild Neurocognitive Disorder Due to Traumatic Brain Injury," and unfortunately the "diagnostic criteria" do not include the majority of patients with the diagnosis of PCS based on DSM-IV or ICD-10. In general, DSM-V only recognizes patients with loss of consciousness (LOC), posttraumatic amnesia, disorientation, or focal neurological signs such as hemiparesis or abnormal neuroimaging; thus, in our view, DSM-V is not useful for assessing patients with PCS. ${ }^{8}$ In our view, the ICD-10 and DSM definitions and changes are arbitrary and without a clear scientific basis with respect to the list of eligible symptoms, the 3-month requirement, and the recategorization. In view of the lack of unanimity about the definition of PCS, we used an inclusive definition of PCS as any 3 or more postconcussion symptoms persisting for at least 1 month. We excluded all head injuries that resulted in a hemorrhage, contusion, or a moderate to severe traumatic brain injury (TBI). The head injury must have been a concussion that conforms to the 4th International Consensus Conference on Concussion in Sport. ${ }^{27}$ The criteria for PCS according to the ICD-10, DSM-IV, and the definition used in this study are shown in Table 1.

Table 2 lists all the potential predictors of PCS previously cited in the literature and categorized into preinjury, injury, and postinjury predictors. There is no unanimity about the validity of most of these predictors. One of the most commonly cited predictors is premorbid psychiatric illness, ${ }^{10,14,25,32,39}$ including depression, ${ }^{12,26}$ anxiety, ${ }^{12,19-21}$ and posttraumatic stress disorder (PTSD). ${ }^{26,39}$ Other predictors include learning disabilities,${ }^{44}$ migraine headaches, ${ }^{19}$ females,,${ }^{1,4-6,10,12,13,26,32,39}$ older age, ${ }^{18,21,39}$ and children and adolescents. ${ }^{15,27}$ Lastly, those with previous concussions are believed to have an increased risk of PCS, $3,7,13,19,27,32,44$ although the exact number required to increase the risk is unknown.

The purposes of the present study were to examine the demographic and etiological features of PCS in a large retrospective cohort and to identify any predictors. We also aimed to determine whether there were any differences in

TABLE 1. Definitions of postconcussion syndrome

\begin{tabular}{|c|c|c|c|}
\hline Variable & WHO ICD-10 (1992) ${ }^{42,43}$ & DSM-IV² & Our Definition \\
\hline $\begin{array}{l}\text { Essential compo- } \\
\text { nents }\end{array}$ & $\begin{array}{l}\text { Head trauma ... } \\
\text { 1. "usually sufficiently severe to result } \\
\text { in loss of consciousness" } \\
\text { 2. "preceding the onset of symptoms } \\
\text { by a period of up to } 4 \text { wks" }\end{array}$ & $\begin{array}{l}\text { 1. "Evidence from neuropsychological testing or } \\
\text { quantified cognitive assessment of difficulty in } \\
\text { attention or memory" } \\
\text { 2. Symptoms occur after head injury or pre-exist- } \\
\text { ing symptoms worsen } \\
\text { 3. Impairs social/occupational functioning } \\
\text { 4. Does not result in dementia or cannot be better } \\
\text { explained by another mental disorder }\end{array}$ & $\begin{array}{l}\text { 1. The concussion was not associ- } \\
\text { ated w/ moderate or severe TBI: } \\
\text { hemorrhage, cerebral contusion, } \\
\& \text { focal neurological deficits are } \\
\text { excluded }\end{array}$ \\
\hline No. of symptoms & At least 3 from the list below & $\begin{array}{l}\text { At least } 3 \text { from the list below + difficulty in attention } \\
\text { or memory }\end{array}$ & $\begin{array}{l}\text { Any } 3 \text { symptoms from the list of } 40 \\
\text { symptoms shown in Table } 6\end{array}$ \\
\hline \multirow[t]{8}{*}{ Eligible symptoms } & Headache & Headache & \multirow[t]{8}{*}{ See Table 6} \\
\hline & Dizziness & Dizziness or vertigo & \\
\hline & Fatigue & Fatigue & \\
\hline & Irritability & Irritability or aggression on little provocation & \\
\hline & Insomnia & Disordered sleep & \\
\hline & Memory problems & Personality changes & \\
\hline & Concentration issues & Apathy & \\
\hline & $\begin{array}{l}\text { Reduced tolerance to stress, emotion- } \\
\text { al excitement, or alcohol }\end{array}$ & Anxiety or depression & \\
\hline $\begin{array}{l}\text { May also have } \\
\text { these symptoms: }\end{array}$ & Depression, anxiety & $\begin{array}{l}\text { Visual or hearing impairments, anosmia, orthope- } \\
\text { dic \&/or neurological complications, substance- } \\
\text { related disorders }\end{array}$ & Not applicable \\
\hline Duration of PCS & Does not specify the duration & At least 3 mos & At least $1 \mathrm{mo}$ \\
\hline
\end{tabular}


TABLE 2. Potential predictors of PCS cited in the literature*

\begin{tabular}{|c|c|c|}
\hline Predictor & Qualifier & References \\
\hline \multicolumn{3}{|l|}{ Preinjury predictors of PCS } \\
\hline Age & $\begin{array}{l}\text { Increased risk w/ older age (above age 40, but the exact age of increased } \\
\text { risk is unknown); also increased risk in children \& adolescents }\end{array}$ & $8,15,18,21,27$ \\
\hline Learning disabilities \& ADD/ADHD & Increased risk w/ previous history of a learning disability or ADD/ADHD & 44 \\
\hline Migraines & Increased risk w/ history of migraine & 19 \\
\hline No. of previous concussions & Increased risk w/ previous concussions & $3,7,13,19,27,32,44$ \\
\hline Psychiatric conditions & Depression, anxiety, \& PTSD & $\begin{array}{l}10,12,14,19,21,25,26,32 \\
\quad 39,44\end{array}$ \\
\hline Sex & Females are at increased risk & $1,4,5,6,10,12,13,26,32,39$ \\
\hline Socioeconomic status & Those of lower income \& less education are at increased risk & 5,39 \\
\hline Substance abuse & Increased risk w/ substance abuse of alcohol or drugs & 24 \\
\hline \multicolumn{3}{|l|}{ Injury predictors of PCS } \\
\hline Amnesia \&/or LOC & Increased risk if there was amnesia \&/or LOC at time of injury & 19,41 \\
\hline Extracranial injuries & Increased risk if extracranial injuries sustained at the time of injury & $5,18,33$ \\
\hline GCS score & $\begin{array}{l}\text { Increased risk w/ GCS score < } 15 \text { (13 or 14), \& correlated w/ abnormal brain } \\
\text { CT/MR scans }\end{array}$ & 23,28 \\
\hline Mechanism of injury & $\begin{array}{l}\text { Increased risk w/ motor vehicle accidents, falls, \& assaults; decreased risk } \\
\text { w/ sports \& recreation }\end{array}$ & $4,6,12,32$ \\
\hline \multicolumn{3}{|l|}{ Postinjury predictors of PCS } \\
\hline Litigation & Increased risk if patient involved in litigation about the injury & $9,11,31$ \\
\hline
\end{tabular}

* The predictors are presented in alphabetical order, thus the order is not indicative of the strength of the predictor.

predictors if the ICD-10 or DSM-IV definitions were used. Our long-term aims are to develop strategies to prevent and treat PCS and to determine whether PCS is an antecedent to chronic traumatic encephalopathy (CTE).

\section{Methods \\ Study Design and Patients}

This study was a retrospective chart review approved by the Research Ethics Board of the University Health Network in Toronto, Canada. All consecutive patients seen in consultation by 1 neurosurgeon (C.H.T.) with a specific interest in PCS were considered for this study. All patients diagnosed with a concussion from January 1997 to June 2013 were identified from clinical records by a single researcher (H.S.D.). Data extraction from medical records was also performed by this researcher. All information including definitive diagnoses was clearly outlined in the clinical notes and other findings from imaging and other tests.

This study defined concussion according to the 4th International Consensus Conference on Concussion in Sport. ${ }^{27}$ Although most of the cases evaluated in the clinic antedated this conference, this definition of concussion was rigorously used to select patients for inclusion. It should be noted that the Glasgow Coma Scale (GCS) score is not a factor in this definition of concussion. Moreover, for the present study of PCS, patients were excluded if they had any lesions on routine MRI or CT scans because such lesions indicate the presence of more severe injuries such as cerebral contusion or intracranial hemorrhage.

As noted above, patients were considered to have PCS if they had any 3 or more postconcussion symptoms per- sisting for at least 1 month. Patients were excluded if they did not meet this specific definition of PCS or if they had a more severe brain injury. Of the 284 consecutive patients with concussions, 63 were excluded for the reasons stated in Table 3, leaving a sample of 221. It is interesting to note that $21(7.4 \%)$ of the 284 cases referred as concussions were excluded due to focal neurological deficits, which indicated brain injuries more severe than concussion (Table 3 ), and these cases were excluded on the basis of imaging. One hundred thirty-eight (62.4\%) of the 221 accepted cases sustained their most recent concussion in sports and recreation. They are included in the present study, but certain features of this group were recently reported. ${ }^{38}$

\section{Data Collection}

The data collected from the patients' clinical charts were from many sources including clinician's notes, neuropsychological reports, imaging reports, referring physicians' notes, other physicians' notes, Sport Concussion Assessment Tools versions 2 and 3, and patient self reports. A total of 50 different symptoms were recorded from these sources, along with demographic information, previous medical history, imaging performed, duration of symptoms, medications, and other treatments. A total of 77 different variables were recorded.

\section{Statistical Analysis}

Chi-square tests were used to compare the prevalence of incidental findings in the patients versus the general population. Statistical significance was set at $p \leq 0.05$ before the analysis was conducted. This statistical test was conducted using Microsoft Excel. 
TABLE 3. List of patients excluded and reasons for exclusion

\begin{tabular}{lr}
\hline \multicolumn{1}{c}{ Reason for Exclusion } & Value (\%) \\
\hline Fewer than 3 symptoms & $15(23.8)$ \\
\hline Symptoms for less than 1 mo & $16(25.4)$ \\
\hline $\begin{array}{l}\text { Fewer than } 3 \text { symptoms \& symptoms for less than } 1 \text { mo } \\
\text { (not included in previous 2 categories) }\end{array}$ & $11(17.5)$ \\
\hline Intracerebral hemorrhage & $3(4.8)$ \\
\hline Cerebral contusion & $6(9.5)$ \\
\hline Subarachnoid hemorrhage \& cerebral contusion & $2(3.2)$ \\
\hline Subdural \&/or epidural hematoma & $3(4.8)$ \\
\hline Intracerebral hematoma \& cerebral contusion & $1(1.6)$ \\
\hline $\begin{array}{l}\text { No PCS \& brain injury more severe than concussion } \\
\text { (not included in any of the above categories) }\end{array}$ & $6(9.5)$ \\
\hline Total exclusions & $63(100)$ \\
\hline
\end{tabular}

To evaluate this heterogeneous, multivariate data set in a principled way, the data were analyzed as follows. Variables were separated into a set of predictors and outcomes, with predictors consisting of age, sex, number of previous concussions, prior history of psychiatric conditions, prior history of migraines, cause of injury (sports or otherwise), presence of extracranial injuries, occurrence of amnesia or LOC, and the patient's involvement in litigation. Outcomes consisted of the number of reported symptoms, and the duration of PCS. The number of symptoms played a dual role, acting as an outcome to be predicted in one analysis and as an additional predictor for the analysis of PCS duration. The variables age, number of previous concussions, and number of symptoms were all heavily skewed toward lower values, so these data were log-transformed to better approximate normally distributed variables. Analyses conducted with or without these log-transformations produced qualitatively similar results.

Four multivariate analyses were performed to explore the correlational structure among the predictors, and to evaluate their capacity to predict the two outcomes. The first analysis searched for the presence of statistically significant pairwise associations among all predictors (including the number of symptoms). The nonparametric Spearman's rank correlation was used for pairs of continuous variables, the chi-square test for pairs of categorical variables, and the nonparametric Wilcoxon rank-sum test for continuous/categorical variable pairs. Compensation for multiple comparisons $(10 \times(10-1) / 2=45$ tests $)$ was achieved by controlling for a false discovery rate of $p=$ 0.05 .

The second analysis explored the clustering of variables implied by the pairwise associations with a principal components analysis. All predictors were standardized to have zero mean and unit variance so that their component scores could be meaningfully compared regardless of measurement units. The variance captured by each component and the component scores were examined, and the significance of components was established via permutation testing (10,000 iterations).

The third test examined the ability to predict the number of symptoms reported using multiple linear regression over the remaining variables. Again, standardized predic- tors were used so the regression coefficient values could be compared. In addition to the analysis of the full model incorporating all predictors, a stepwise analysis was also conducted to identify the most parsimonious model with the fewest predictors.

The fourth analysis attempted to forecast the duration of PCS using all predictors, including the number of reported symptoms. This analysis is complicated by the fact that for patients who have recovered, we know exactly how long their PCS lasted, but for those who have not yet recovered, we know only that their PCS has lasted at least as long as the time from injury to the last consultation. The Cox proportional hazards model was selected to assess the effect of predictor variables on the rate at which an event of interest occurs. In this study, the event of interest is recovery from concussion, and the outcome variable is the time elapsed from concussion to recovery. If recovery had not yet occurred at the time of the last consultation, then the time elapsed from injury to consultation date was recorded and the data were flagged as censored. All analyses were performed using Matlab and its Statistics Toolbox Release 2014b (The MathWorks, Inc.).

Finally, because the criteria for PCS used in this work are novel, the above analyses were repeated for the subsets of patients corresponding to the ICD-10 and DSM-IV definitions and the results compared.

\section{Results}

\section{Demographic Features}

The cohort consisted of 127 males (57.5\%) and 94 females (42.5\%; Table 4). The mean age at the time of the most recent concussion was 27.0 years, and the median age was 20 years, with a range of ages from 10 to 74 years.

TABLE 4. Demographic characteristics in 221 patients

\begin{tabular}{cc}
\hline Demographic Variable & Value $(\%)$ \\
\hline Sex & $127(57.5)$ \\
\hline Male & $94(42.5)$ \\
\hline Female & $21(9.5)$ \\
\hline Comorbidity & $18(8.1)$ \\
\hline Migraines & $17(7.7)$ \\
\hline Depression & $9(4.1)$ \\
\hline Anxiety & $6(2.7)$ \\
\hline Learning disability & $5(2.3)$ \\
\hline ADHD & $3(1.4)$ \\
\hline Sleep disorder & $2(0.9)$ \\
\hline ADD & $2(0.9)$ \\
\hline Eating disorder & $2(0.9)$ \\
\hline Postpartum depression & $1(0.5)$ \\
\hline Substance abuse & $1(0.5)$ \\
\hline Bipolar disorder & $1(0.5)$ \\
\hline Dysgraphia & $1(0.5)$ \\
\hline Hypochondriasis & $1(0.5)$ \\
\hline OCD &
\end{tabular}

$\mathrm{OCD}=$ obsessive-compulsive disorder. 


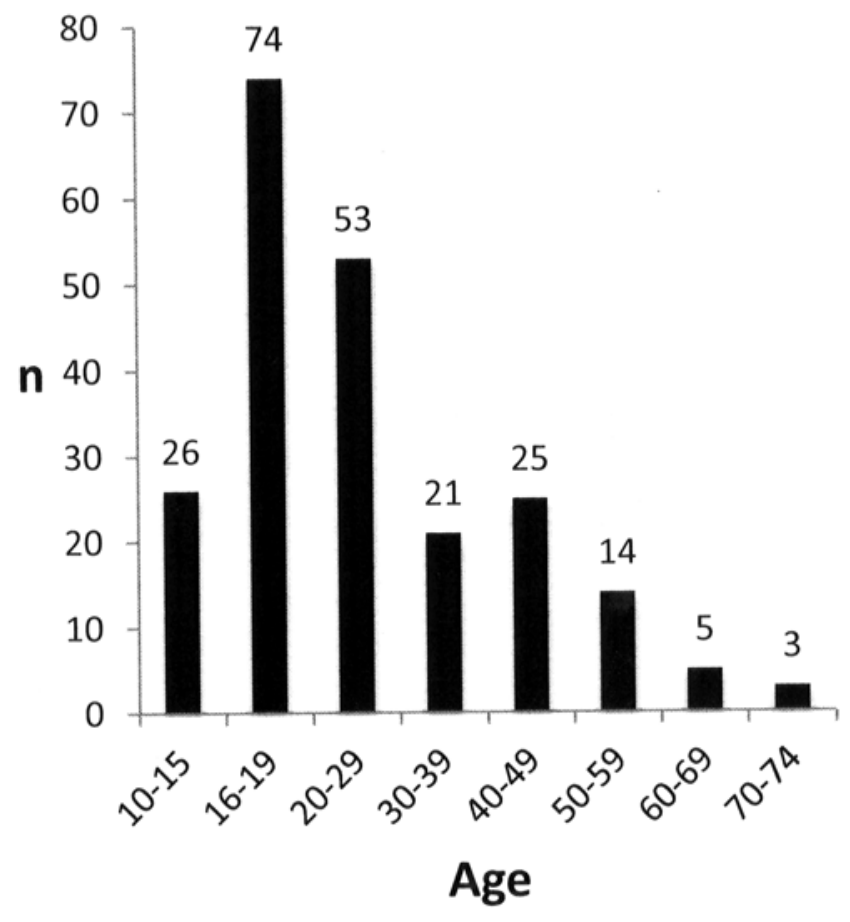

FIG. 1. Graph showing the ages of patients at the time of their most recent concussion.

One hundred patients $(45.2 \%)$ were between the ages of 10 and 19 (Fig. 1). The average number of total concussions (including the most recent that was the cause of the consultation) was 3.3 , and the median number of total concussions was 3 (Fig. 2). Fifty-eight patients (26.2\%) had a history of 1 of the following comorbidities prior to their concussion: previous migraine headaches, psychiatric illness, learning disability, and/or attention-deficit disorder (ADD)/attention-deficit hyperactivity disorder (ADHD). Twenty-one patients $(9.5 \%)$ were involved in litigation related to the concussion.

\section{Concussion Details}

The median time interval from the last concussion to consultation was 4 months, with a range of 4 days to 26 years (Fig. 3). The mean and median duration of PCS were 14.7 and 7 months, respectively, with a range of 1 month to 26 years (Fig. 4). In $11.8 \%$ the PCS lasted more than 2 years, and $23.1 \%$ with PCS had only 1 concussion. In only 25 patients (11.3\%), the PCS had resolved completely at the time of the last examination. Forty-three patients (19.5\%) lost consciousness in the last concussion, and 72 patients (32.6\%) had amnesia. Fifty-seven patients (25.8\%) were prescribed medications to manage their symptoms prior to the consultation, $36(63.2 \%)$ of whom were prescribed antidepressants.

With respect to the etiology of the most recent concussion, $138(62.4 \%)$ occurred in sports and recreation, with $72(52.2 \%)$ in ice hockey (Table 5). Motor vehicle crashes caused $23(10.4 \%)$ of the most recent concussions, falls caused 19 (8.6\%), and school-related activity caused 17 (7.7\%).

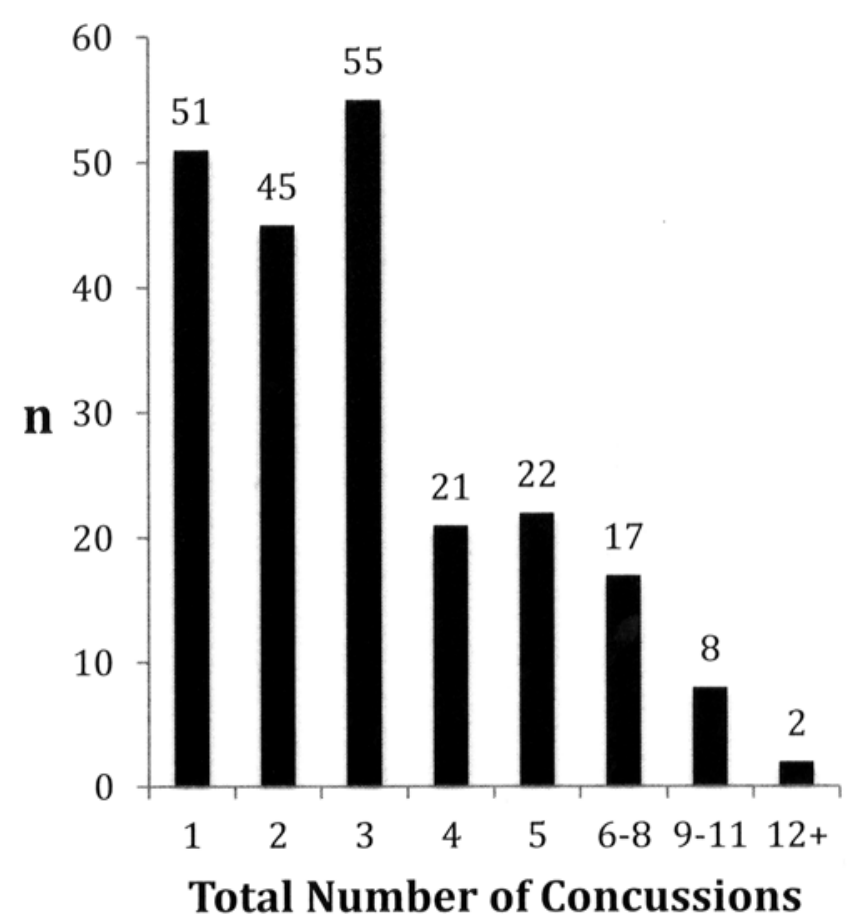

FIG. 2. Graph of the total number of concussions per patient, including the most recent concussion.

\section{Persistent Symptoms}

The average number of persistent symptoms was 8.1, with a range of 3 to 23 persistent symptoms; the most common were headaches, memory deficits, concentration difficulties, imbalance, and dizziness (Table 6).

\section{Imaging and Other Diagnostic Tests Prior to or After the Concussion}

Thirty-two patients (14.5\%) had a CT scan prior to consultation, and 71 (32.1\%) underwent MRI before consultation. As a result of the consultation, an additional 69 (31.2\%) had MRI. Twelve (5.4\%) underwent MRI both before and after consultation. A total of 184 patients (83.3\%) had MRI and/or CT, either before or after the consultation. Some incidental findings were discovered by the imaging, including an arachnoid cyst in $8(3.6 \%)$ and Chiari malformation in $10(4.5 \%)$. One patient required surgical decompression for the Chiari malformation after the concussion. A significantly greater proportion of PCS sufferers in this study had an arachnoid cyst and Chiari malformation compared with the prevalence of these conditions in the general population: $4.5 \%$ of patients had a Chiari malformation, while the prevalence of Chiari malformation in the general population is $0.00078 \%(\mathrm{p}<0.0000005) .^{29,35}$ Arachnoid cysts were present in $3.6 \%$ of patients, whereas the prevalence in the general population ranges from $0.006 \%$ to $1.7 \%$ ( $p<0.00005$ and $\mathrm{p}=0.09$, respectively). Thirty-eight patients (17.2\%) underwent neuropsychological testing to evaluate cognitive deficits: $10(26.3 \%)$ had results within the normal ranges, $25(65.8 \%)$ had cognitive deficits, and in $3(7.9 \%)$ the results are unknown. 


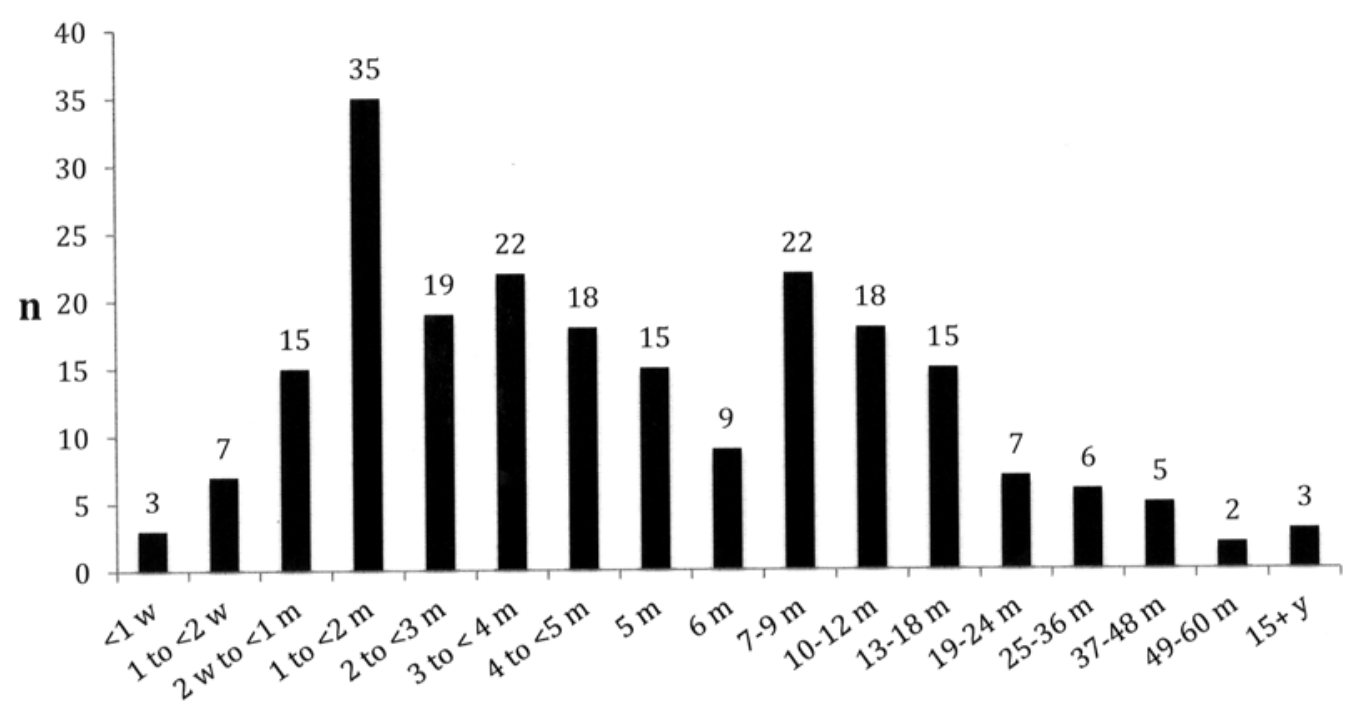

Time Interval

FIG. 3. Graph of the time interval from the most recent concussion until consultation with the neurosurgeon (C.H.T.). $m=$ months, $y=$ years.

\section{Associations Between Predictors}

The results from the analysis of associations between predictors are illustrated in Table 7. The table has 1 entry for each unique pair of predictors. Since associations are symmetric, only the lower triangle of the matrix is included. The positive symbols ("+") indicate positive associations, while the 1 negative symbol ("-") indicates a negative association, where the sign of the association is determined with reference to the coding of the variables described in the table caption. For example, the significant positive association between the number of reported symptoms and cause of concussion (coded as 0 for sports and 1 for other causes), indicates that concussions suffered during sporting activity are associated with fewer reported symptoms compared with other causes. In contrast, the significant negative association between the number of previous concussions and sex (coded as 0 for males and 1 for females) indicates that females reported fewer concussions than males prior to the key injury that led to the consultation. Of 45 tests of association, 17 were found to be statistically significant after controlling the false discovery rate (at $\mathrm{p}=0.05)$.

\section{Principle Components Analysis}

The principal components analysis revealed only a weak overall correlation among the predictors, with the

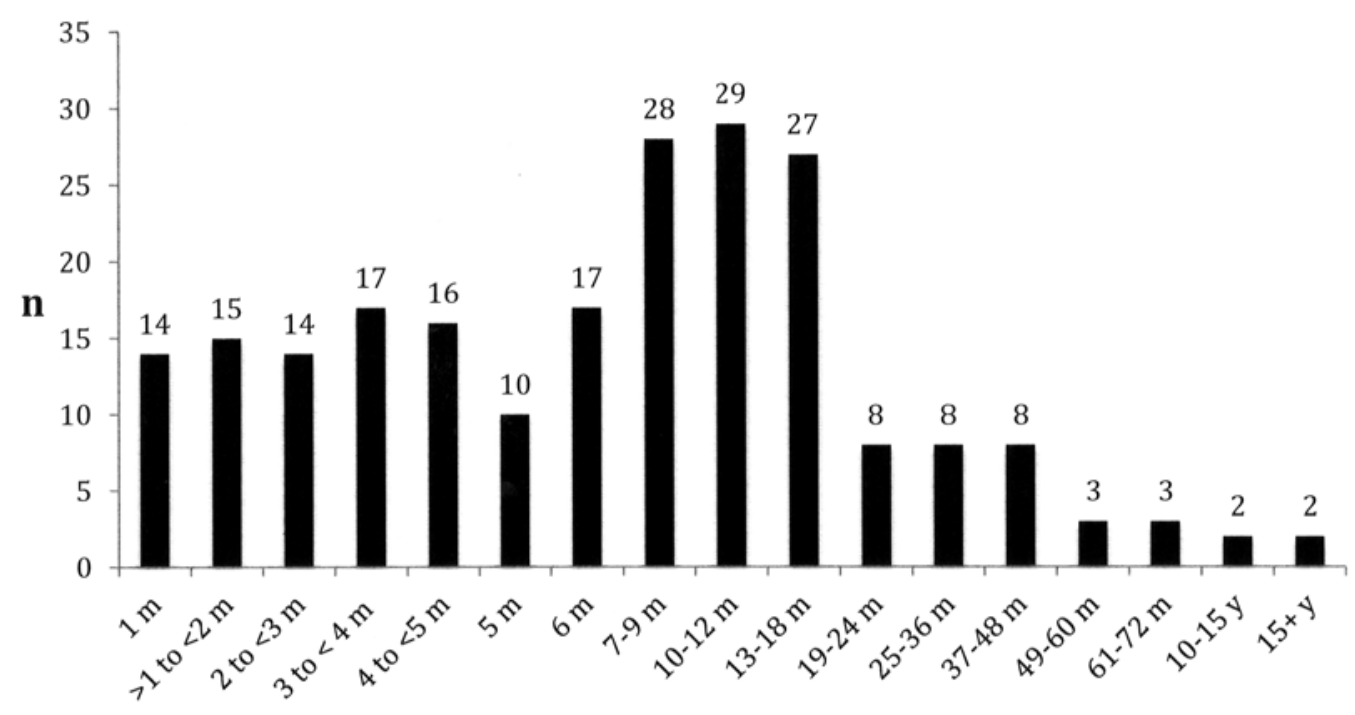

Time Interval

FIG. 4. Graph of the duration of PCS symptoms from the most recent concussion. In many patients, the total duration would be longer because the PCS had not resolved completely at the time of their last examination. $m=$ months, $y=$ years. 
TABLE 5. Cause of most recent concussion

\begin{tabular}{|c|c|}
\hline Concussion Cause & Value (\%) \\
\hline Sports \& recreation & $138(62.4)$ \\
\hline Winter sports & $87(39.4)$ \\
\hline Ice hockey* & $72(32.6)$ \\
\hline Skiing* & $8(3.6)$ \\
\hline Snowboarding* & $4(1.8)$ \\
\hline Field sports & $22(10.0)$ \\
\hline Soccer* & $12(5.4)$ \\
\hline Rugby* & $3(1.4)$ \\
\hline Floor sports & $8(3.6)$ \\
\hline Basketball* $^{*}$ & $4(1.8)$ \\
\hline Equestrian & $6(2.7)$ \\
\hline Water sports & $5(2.3)$ \\
\hline Bicycling & $3(1.4)$ \\
\hline Motor sports & $3(1.4)$ \\
\hline Snowmobile* & $2(0.9)$ \\
\hline Miscellaneous & $2(0.9)$ \\
\hline Racquet sports & $1(0.5)$ \\
\hline Summer sports & $1(0.5)$ \\
\hline Motor vehicle crash & $23(10.4)$ \\
\hline Driver & $13(5.9)$ \\
\hline Passenger & $4(1.8)$ \\
\hline Cyclist & $1(0.5)$ \\
\hline Pedestrian & $1(0.5)$ \\
\hline Motorcycle & $1(0.5)$ \\
\hline Falls & $19(8.6)$ \\
\hline School-related & $17(7.7)$ \\
\hline Team sport - university/college varsity† & $8(3.6)$ \\
\hline Team sport - elementary/high school† & $3(1.4)$ \\
\hline Roughhousing & $2(0.9)$ \\
\hline Fighting & $1(0.5)$ \\
\hline Gym class $\uparrow$ & $1(0.5)$ \\
\hline Lunch/recess & $1(0.5)$ \\
\hline Work-related & $7(3.2)$ \\
\hline Assault & $6(2.7)$ \\
\hline Falling object & $4(1.8)$ \\
\hline Striking object & $4(1.8)$ \\
\hline Roughhousing & $2(0.9)$ \\
\hline Other & $1(0.5)$ \\
\hline Total & 221 \\
\hline
\end{tabular}

* Specific sport/recreational activity was listed if more than 1 concussion occurred in this activity.

$\dagger$ Concussions that occurred in a school setting were categorized under school-related, even if they occurred from sports and recreation activities.

strongest 3 components accounting for $22.4 \%, 12.8 \%$, and $11.4 \%$ of the variance among the standardized predictors, and the remaining 7 components falling between 9.4\% and $5.3 \%$. Visual inspection of a 3D scatterplot of the first 3 components revealed no discernible clustering pattern among the predictors. Only the first principal component was statistically significant at $\mathrm{p}<0.05$ as assessed by per-
TABLE 6. Most common persisting symptoms in PCS

\begin{tabular}{lc}
\hline \multicolumn{1}{c}{ Persistent Symptoms } & No. (\%) \\
\hline Headaches & $197(89.1)$ \\
\hline Memory deficits & $136(61.5)$ \\
\hline Concentration difficulties & $124(56.1)$ \\
\hline Imbalance & $115(52.0)$ \\
\hline Dizziness & $114(51.6)$ \\
\hline Fatigue & $101(45.7)$ \\
\hline Nausea & $95(43.0)$ \\
\hline Sensitivity to light & $86(38.9)$ \\
\hline Sleeping problems (insomnia, sleeping too much \&/or & $72(32.6)$ \\
\hline too little) & \\
\hline Irritability & $70(31.7)$ \\
\hline Depression & $68(30.8)$ \\
\hline Vision changes (blurry vision, double vision, unspeci- & $63(28.5)$ \\
\hline fied) & \\
\hline Anxiety & $51(23.1)$ \\
\hline Mental fogginess ("don't feel right," dazed, feeling in a & $50(22.6)$ \\
\hline fog) & \\
\hline Sensitivity to noise & $49(22.2)$ \\
\hline Neck pain & $40(18.1)$ \\
\hline Tinnitus & $37(16.7)$ \\
\hline Increased emotionality & $36(16.3)$ \\
\hline Pressure in the head & $29(13.1)$ \\
\hline Lightheadedness & $27(12.2)$ \\
\hline Personality changes & $24(10.9)$ \\
\hline Vertigo & $22(10.0)$ \\
\hline Confusion & $21(9.5)$ \\
\hline Numbness & $21(9.5)$ \\
\hline Feeling slowed down & $17(7.7)$ \\
\hline Learning difficulties & $17(7.7)$ \\
\hline Loss of appetite & $14(6.3)$ \\
\hline Vomiting & $10(4.5)$ \\
\hline Panic attacks & $8(3.6)$ \\
\hline Thinking time increased & $8(3.6)$ \\
\hline Frustrated & $7(3.2)$ \\
\hline Increased sensitivity to alcohol & $7(3.2)$ \\
\hline Speech problems & $7(3.2)$ \\
\hline Seizures & $3(1.4)$ \\
\hline Aggression & $2(0.9)$ \\
\hline Problem-solving difficulties & $2(0.9)$ \\
\hline Response speed slowed & $2(0.9)$ \\
\hline Restlessness & $2(0.9)$ \\
\hline Stomach ache & $2(0.9)$ \\
\hline Total & $1(0.5)$ \\
\hline &
\end{tabular}

mutation testing, with all component scores positive except for number of previous concussions (Table 8). Thus, the single axis that explained the greatest variance-although still relatively little at $22.4 \%$-corresponded in one direction to older females with a history of migraines and pre- 
TABLE 7. Associations among predictor variables*

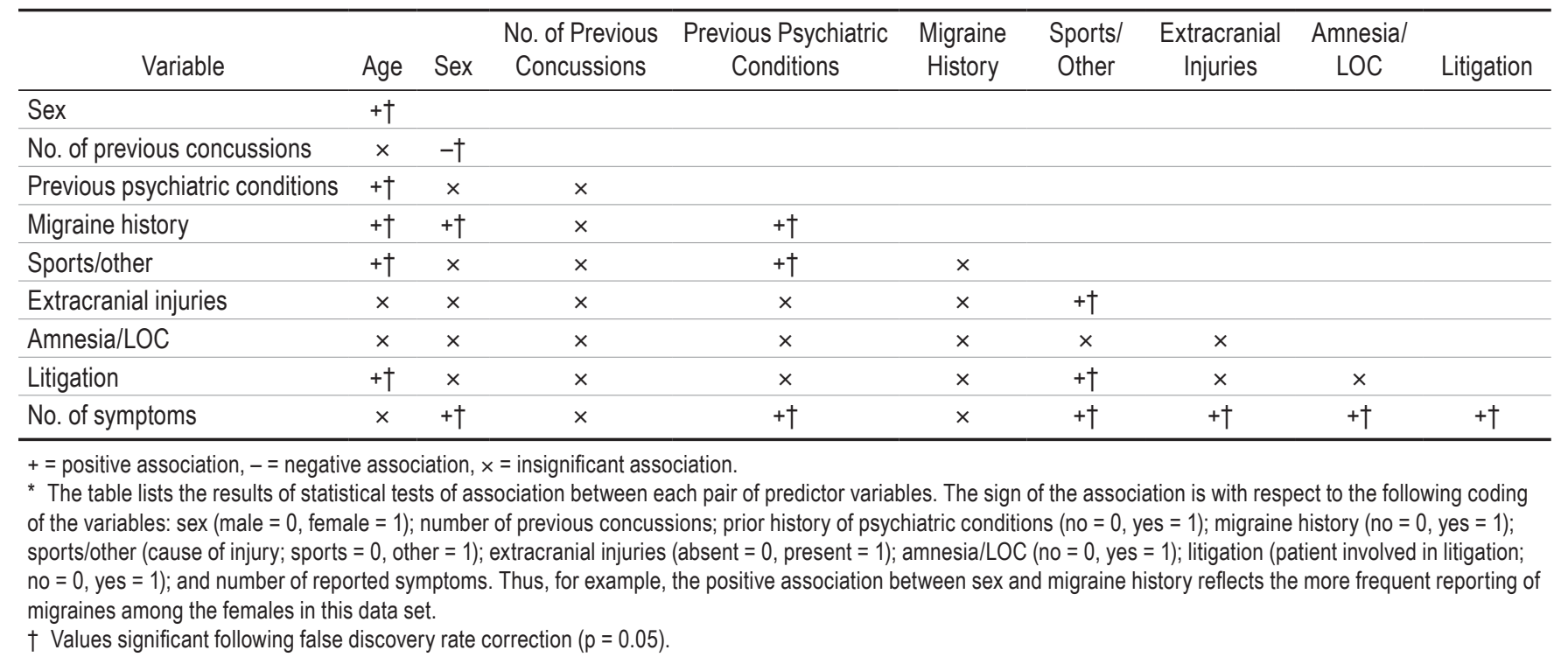

vious psychiatric conditions, reporting many symptoms following a concussion that included extracranial injuries and either amnesia or LOC, sustained in a nonsporting activity, followed by litigation, but reporting fewer prior concussions. In the opposite direction, the axis describes younger males with no history of migraines or previous psychiatric conditions, reporting fewer symptoms following a concussion that did not include extracranial injuries, amnesia, or an LOC, sustained during a sporting activity, not resulting in litigation, but reporting a larger number of prior concussions.

\section{Predicting the Number of Symptoms}

The results of the multiple linear regression analysis aimed at predicting the number of reported symptoms is shown in Table 9. Of the 9 predictors tested for the ability to predict the number of symptoms, only the patient

TABLE 8. Coefficient scores for the one significant principal component*

\begin{tabular}{|c|c|}
\hline Variable & $\begin{array}{c}\text { Component } \\
\text { Score }\end{array}$ \\
\hline Age & 0.441 \\
\hline Cause of injury (sports = 0 , other $=1$ ) & 0.407 \\
\hline No. of symptoms & 0.354 \\
\hline Prior history of migraines (no $=0$, yes $=1$ ) & 0.332 \\
\hline Sex $($ male $=0$, female $=1)$ & 0.305 \\
\hline Extracranial injuries (no $=0$, yes $=1$ ) & 0.290 \\
\hline Involved in litigation (no = 0 , yes $=1$ ) & 0.284 \\
\hline Prior history of psychiatric condition (no = 0 , yes $=1$ ) & 0.278 \\
\hline Amnesia/LOC reported $($ no $=0$, yes $=1$ ) & 0.196 \\
\hline No. of previous concussions & -0.178 \\
\hline
\end{tabular}

* This component accounted for $22.4 \%$ of the variance among the standardized predictors. The variables are listed in order of decreasing component score magnitude. involvement in litigation was statistically significant $(\mathrm{p}$ $=0.006)$, with the presence of extracranial injuries $(\mathrm{p}=$ $0.054)$ and the occurrence of amnesia or LOC $(p=0.063)$ trending toward significance. A stepwise regression procedure yielded a model with the same 3 predictors in addition to sex as statistically significant in the most parsimonious model. The results suggest that involvement in litigation, presence of extracranial injuries, occurrence of amnesia and/or LOC, and being female were the most important predictors for reporting a larger number of symptoms. These results are consistent with the correlations reported in Table 7.

\section{Predicting the Duration of PCS}

The Cox proportional hazards model identified the reported number of symptoms as the only statistically significant predictor of PCS duration ( $\mathrm{p}=0.0045)$, with a linear coefficient of -0.302 , amounting to a $25 \%$ reduction in the recovery rate for each additional symptom. The number of symptoms was not log-transformed for this analysis, as a better fit was achieved using the original linear scale. Even with this predictor removed, none of the other predictors approached statistical significance. However, the weak performance of the other predictors is understandable given the under-constrained condition of the model, with only $25(11.6 \%)$ of the 215 patients having a known recovery time and all others with ongoing PCS that may or may not resolve at some future unknown date.

\section{Predictors of ICD-10 and DSM-IV}

When the analyses reported above were repeated using only the subsets of the data corresponding to the ICD-10 (146 patients) and DSM-IV (101 patients) definitions of PCS, the most significant trend was toward a general reduction in statistical significance commensurate with the substantially smaller numbers of patients. For the analysis of predictor associations, only 6 of the 45 associations were significant for the ICD-10 set, and only 1 for the DSM-IV 
TABLE 9. Results of multiple linear regression to predict the number of symptoms*

\begin{tabular}{lccc}
\hline & & \multicolumn{2}{c}{ Statistical Significance } \\
\cline { 3 - 4 } Variable Name & Standardized Regression Coefficient \pm SE & Full Model & Stepwise Regression \\
\hline Litigation & $0.091 \pm 0.033$ & 0.006 & 0.002 \\
\hline Extracranial Injuries & $0.064 \pm 0.033$ & 0.054 & 0.023 \\
\hline Amnesia/LOC & $0.060 \pm 0.032$ & 0.063 & 0.034 \\
\hline Prior history of psychiatric conditions & $0.054 \pm 0.033$ & 0.104 & - \\
\hline Sex & $0.053 \pm 0.034$ & 0.117 & - \\
\hline Cause of injury (sports or other) & $0.033 \pm 0.035$ & 0.347 & - \\
\hline Prior history of migraines & $0.029 \pm 0.034$ & 0.401 & - \\
\hline No. of previous concussions & $-0.022 \pm 0.033$ & 0.501 & - \\
\hline Age & $-0.017 \pm 0.037$ & 0.635 & \\
\hline SE $=$ standard error. & & & \\
* The list of symptoms is sorted in order of decreasing statistical significance in the full model. The standardized coefficients from the stepwise \\
regression were not significantly different from those in the full model.
\end{tabular}

set. For the principal components analysis, the results were qualitatively identical to the main analysis, with some minor variations in the magnitudes of the factor scores. For the models aimed at predicting the number of symptoms and the PCS duration, the relative ordering of importance of the variables was largely preserved with one interesting exception: for both predictive models, for both the ICD-10 and DSM-IV sets, the one qualitative difference observed was an increase in the importance of the number of previous concussions. This variable had not been among the highest ranked in any of the main analyses using our new definition of PCS, but was the most important predictor of the number of symptoms and the PCS duration (though still not statistically significant) for both the ICD-10 and DSM-IV subsets.

\section{Discussion}

The present study is unique because a uniform definition of concussion was applied to all cases based on the 4th International Consensus Conference on Sports Concussions $^{27}$ and because a new definition of PCS was used consisting of any 3 symptoms lasting at least 1 month. This is a novel, working definition of PCS that is based on the internationally accepted definition of concussion, which has not been well integrated into research. Also, we specifically excluded brain injuries more severe than concussion, such as intracranial hemorrhages, contusions, and focal neurological deficits. Table 3 shows that $7.4 \%$ of cases were excluded because of focal intracranial pathology. Most previous studies of PCS used other definitions of concussion and PCS and included a heterogeneous population of cases, including those with focal pathological lesions and a GCS score of 13-15 and labeled mild TBI.

As observed in other studies, the most common symptom of PCS in the present study was headache. ${ }^{16,19,22}$ However, unlike other studies, our patients had a much higher prevalence of previous concussions, with $76.9 \%$ in the current series having at least 1 previous concussion (Fig. 2 ), compared with a range of $22 \%-53 \%$ in other studies. $6,12,15,30,32$ Many of these studies were based on emergency department visits, or visits to the offices of pedi- atricians or general practitioners, and thus focused on a different population of patients compared with the present study. The differences in the incidence of previous concussions may also relate to the variations in definition of concussion. Our aim was to achieve complete documentation of all previous concussions because we considered this essential to the long-term goal of our project, which is to determine the role of previous concussions and PCS as antecedents of CTE.

Many other studies have shown an increased risk of PCS in females, ${ }^{4,67,713,26,32}$ and this trend is noted in our results as well. In the present series, females experienced significantly more persistent symptoms than males. However, being female was not a strong predictor of the duration of PCS. These data may suggest that PCS was more severe in females because they had more symptoms than males, but females reported fewer previous concussions, which are associated with prolonged recovery and an increased risk of PCS. .7, $, 19,27,44$ Thus, it is possible females are more susceptible to PCS as fewer concussions can trigger PCS. Females also were more likely to have prior migraine headaches, which have previously been linked to an increased risk of PCS..$^{19}$ However, whether these factors increased the risk of developing PCS in this study is uncertain.

There are studies that support a decreased risk of PCS after concussions in sports and recreation. ${ }^{4,6,32}$ In the present study, the cause of injury did not predict the number of symptoms from PCS sufferers or the duration of PCS.

Only some of the factors previously reported to predict PCS predicted the number of symptoms and the duration of PCS. Involvement in litigation, presence of extracranial injuries, amnesia and/or LOC at the time of concussion, and being female were more likely to report a larger number of symptoms in this study and are variables that have been previously described to be associated with an increased risk of developing PCS (Table 2). Additionally, a prior history of psychiatric conditions or migraines, cause of injury, number of previous concussions, and age did not significantly predict the symptom number. Further comment is limited on this finding as there may not have been sufficient statistical power. 
Another interesting finding is that the number of symptoms was the sole significant predictor for the duration of PCS. For each additional symptom experienced, the recovery rate is reduced by $25 \%$, which is indeed a major factor. This is a crucial finding as all 3 PCS definitions (ICD-10, DSM-IV, and the definition used in this study) require 3 symptoms to fulfill the criteria of the diagnosis of PCS. Thus, it is likely that these criteria need to be reconsidered and these definitions exclude many other patients who are experiencing less than 3 postconcussive symptoms after their concussion. However, the average number of persistent symptoms experienced was approximately 8 , which is well above the required 3 .

When comparing the PCS definition used in this study to the ICD-10 and DSM-IV, the predictive models were largely preserved, except the number of previous concussions was of higher importance in ICD-10 and DSM-IV in predicting the number of symptoms. It is possible that these definitions are biased toward more severe forms of concussions as multiple concussions can prolong recovery. ${ }^{27}$

The findings in this study show distinct differences when different definitions of PCS are used. The DSM-IV definition is no longer in practice and the validity of the ICD-10 definition is questionable. The evidence that supports this definition is lacking. As noted in Table 1, the ICD-10 states that the head trauma that causes PCS is "... usually sufficiently severe to result in loss of consciousness." ${ }^{\prime 2}$ However, less than $15 \%$ of concussions result in LOC. ${ }^{37,38}$ Consequently, it is important for future research to refine the definition of PCS. We are currently working on a follow-up study on this population to determine other factors that may contribute to persistent PCS.

Another important difference was that a significantly greater proportion of PCS sufferers in the present study had incidental findings of arachnoid cysts and Chiari malformations compared with the prevalence in the general population. We are uncertain about the nature of the relationship between these incidental findings and PCS. However, the relationship between trauma and the onset of symptoms from Chiari malformation has been previously recognized.$^{40}$ Due to the mass effect on the brainstem caused by Chiari malformations and the mass effect on the adjacent brain caused by arachnoid cysts, it is possible that the brain moves differently in response to rotational concussive forces in patients with these conditions, and is at greater risk for concussion.

\section{Limitations of the Study}

One of the major limitations in a retrospective study of this nature is a bias in the information that is collected. For example, those with more information in their patient chart had more symptoms recorded, and therefore, the number of persistent symptoms may not accurately represent the severity of PCS. Another limitation is that many patients had only 1 office visit, and therefore the actual duration of the PCS in those patients was longer than recorded. Prospective longitudinal studies on PCS are needed to improve the understanding of this condition, such as its potential role as an antecedent condition leading to CTE. ${ }^{36}$ We have instituted a long-term follow-up study of the patients described in the present report. Lastly, this study was a retrospective cohort review of patients from 1 concussion specialist. The criteria for referral to this concussion specialist are not known, but it is likely that more complicated and persistent cases of PCS were referred. Therefore, a selection bias exists and the patients in this study would not be representative of the general population of concussed patients. Also, as noted, the use of a new definition of PCS should be considered as a potential factor affecting generalizability, and therefore caution must be taken when generalizing these results.

\section{Acknowledgments}

Funds for this study were provided by the Canadian Concussion Centre at the Toronto Western Hospital, which is funded by the Toronto General and Western Hospital Foundation.

\section{References}

1. Alves W, Macciocchi S, Barth J: Postconcussive symptoms after uncomplicated mild head injury. J Head Trauma Rehabil 8:48-59, 1993

2. American Psychiatric Association: Diagnostic and Statistical Manual of Mental Disorders, ed 4. Washington: American Psychiatric Association, 1994

3. American Psychiatric Association: Diagnostic and Statistical Manual of Mental Disorders, ed 5. Arlington: American Psychiatric Publishing, 2013

4. Bazarian JJ, Atabaki S: Predicting postconcussion syndrome after minor traumatic brain injury. Acad Emerg Med 8:788795, 2001

5. Bazarian JJ, Blyth B, Mookerjee S, He H, McDermott MP: Sex differences in outcome after mild traumatic brain injury. J Neurotrauma 27:527-539, 2010

6. Bazarian JJ, Wong T, Harris M, Leahey N, Mookerjee S, Dombovy M: Epidemiology and predictors of post-concussive syndrome after minor head injury in an emergency population. Brain Inj 13:173-189, 1999

7. Benson BW, Meeuwisse WH, Rizos J, Kang J, Burke CJ: A prospective study of concussions among National Hockey League players during regular season games: the NHL-NHLPA Concussion Program. CMAJ 183:905-911, 2011

8. Binder LM: Persisting symptoms after mild head injury: a review of the postconcussive syndrome. J Clin Exp Neuropsychol 8:323-346, 1986

9. Binder LM, Rohling ML: Money matters: a meta-analytic review of the effects of financial incentives on recovery after closed-head injury. Am J Psychiatry 153:7-10, 1996

10. Carroll LJ, Cassidy JD, Holm L, Kraus J, Coronado VG: Methodological issues and research recommendations for mild traumatic brain injury: the WHO Collaborating Centre Task Force on Mild Traumatic Brain Injury. J Rehabil Med 43 (43 Suppl): $113-125,2004$

11. Chan RC: How severe should symptoms be before someone is said to be suffering from post-concussion syndrome? An exploratory study with self-reported checklist using Rasch analysis. Brain Inj 19:1117-1124, 2005

12. Dischinger PC, Ryb GE, Kufera JA, Auman KM: Early predictors of postconcussive syndrome in a population of trauma patients with mild traumatic brain injury. J Trauma 66:289-297, 2009

13. Edna TH, Cappelen J: Late post-concussional symptoms in traumatic head injury. An analysis of frequency and risk factors. Acta Neurochir (Wien) 86:12-17, 1987

14. Evered L, Ruff R, Baldo J, Isomura A: Emotional risk factors and postconcussional disorder. Assessment 10:420-427, 2003

15. Field M, Collins MW, Lovell MR, Maroon J: Does age play a role in recovery from sports-related concussion? A com- 
parison of high school and collegiate athletes. J Pediatr 142:546-553, 2003

16. Guskiewicz KM, Weaver NL, Padua DA, Garrett WE Jr: Epidemiology of concussion in collegiate and high school football players. Am J Sports Med 28:643-650, 2000

17. Iverson GL: Outcome from mild traumatic brain injury. Curr Opin Psychiatry 18:301-317, 2005

18. Jacobs B, Beems T, Stulemeijer M, van Vugt AB, van der Vliet TM, Borm GF, et al: Outcome prediction in mild traumatic brain injury: age and clinical variables are stronger predictors than CT abnormalities. J Neurotrauma 27:655668,2010

19. Jotwani V, Harmon KG: Postconcussion syndrome in athletes. Curr Sports Med Rep 9:21-26, 2010

20. King NS: Emotional, neuropsychological, and organic factors: their use in the prediction of persisting postconcussion symptoms after moderate and mild head injuries. J Neurol Neurosurg Psychiatry 61:75-81, 1996

21. King NS, Kirwilliam S: Permanent post-concussion symptoms after mild head injury. Brain Inj 25:462-470, 2011

22. Lau BC, Kontos AP, Collins MW, Mucha A, Lovell MR: Which on-field signs/symptoms predict protracted recovery from sport-related concussion among high school football players? Am J Sports Med 39:2311-2318, 2011

23. Levin HS, Hanten G, Roberson G, Li X, Ewing-Cobbs L, Dennis M, et al: Prediction of cognitive sequelae based on abnormal computed tomography findings in children following mild traumatic brain injury. J Neurosurg Pediatr 1:461-470, 2008

24. Lishman WA: Physiogenesis and psychogenesis in the 'postconcussional syndrome'. Br J Psychiatry 153:460-469, 1988

25. Luis CA, Vanderploeg RD, Curtiss G: Predictors of postconcussion symptom complex in community dwelling male veterans. J Int Neuropsychol Soc 9:1001-1015, 2003

26. McCauley SR, Boake C, Levin HS, Contant CF, Song JX: Postconcussional disorder following mild to moderate traumatic brain injury: anxiety, depression, and social support as risk factors and comorbidities. J Clin Exp Neuropsychol 23:792-808, 2001

27. McCrory P, Meeuwisse WH, Aubry M, Cantu B, Dvorák J, Echemendia RJ, et al: Consensus statement on concussion in sport: the 4th International Conference on Concussion in Sport held in Zurich, November 2012. Br J Sports Med 47:250-258, 2013

28. McCullagh S, Oucherlony D, Protzner A, Blair N, Feinstein A: Prediction of neuropsychiatric outcome following mild trauma brain injury: an examination of the Glasgow Coma Scale. Brain Inj 15:489-497, 2001

29. Meadows J, Kraut M, Guarnieri M, Haroun RI, Carson BS: Asymptomatic Chiari Type I malformations identified on magnetic resonance imaging. J Neurosurg 92:920-926, 2000

30. Mooney G, Speed J, Sheppard S: Factors related to recovery after mild traumatic brain injury. Brain Inj 19:975-987, 2005

31. Paniak C, Reynolds S, Toller-Lobe G, Melnyk A, Nagy J, Schmidt D: A longitudinal study of the relationship between financial compensation and symptoms after treated mild traumatic brain injury. J Clin Exp Neuropsychol 24:187193,2002

32. Ponsford J, Willmott C, Rothwell A, Cameron P, Kelly AM, Nelms R, et al: Factors influencing outcome following mild traumatic brain injury in adults. J Int Neuropsychol Soc 6:568-579, 2000

33. Prigatano GP, Gale SD: The current status of postconcussion syndrome. Curr Opin Psychiatry 24:243-250, 2011

34. Shenton ME, Hamoda HM, Schneiderman JS, Bouix S, Pasternak O, Rathi Y, et al: A review of magnetic resonance imaging and diffusion tensor imaging findings in mild traumatic brain injury. Brain Imaging Behav 6:137-192, 2012

35. Speer MC, Enterline DS, Mehltretter L, Hammock P, Joseph J, Dickerson M, et al: Chiari Type I malformation with or without syringomyelia: prevalence and genetics. J Genet Couns 12:297-311, 2003

36. Tator $\mathrm{CH}$ : Chronic traumatic encephalopathy: how serious a sports problem is it? Br J Sports Med 48:81-83, 2014

37. Tator $\mathrm{CH}$ : Concussions and their consequences: current diagnosis, management and prevention. CMAJ 185:975-979, 2013

38. Tator $\mathrm{CH}$, Davis $\mathrm{H}$ : The postconcussion syndrome in sports and recreation: clinical features and demography in 138 athletes. Neurosurgery 75 (Suppl 4):S106-S112, 2014

39. Wall PL: Posttraumatic stress disorder and traumatic brain injury in current military populations: a critical analysis. J Am Psychiatr Nurses Assoc 18:278-298, 2012

40. Wan MJ, Nomura H, Tator CH: Conversion to symptomatic Chiari I malformation after minor head or neck trauma. Neurosurgery 63:748-753, 2008

41. Wenden FJ, Crawford S, Wade DT, King NS, Moss NE: Assault, post-traumatic amnesia and other variables related to outcome following head injury. Clin Rehabil 12:53-63, 1998

42. World Health Organization: ICD-10 Classification of Mental and Behavioural Disorders: Clinical Descriptions and Diagnostic Guidelines. Geneva: World Health Organization, 1992

43. World Health Organization: ICD-10 Classification of Mental and Behavioural Disorders: Diagnostic Criteria for Research. Geneva: World Health Organization, 1992

44. Zemek RL, Farion KJ, Sampson M, McGahern C: Prognosticators of persistent symptoms following pediatric concussion: a systematic review. JAMA Pediatr 167:259-265, 2013

\section{Disclosures}

The authors report no conflict of interest concerning the materials or methods used in this study or the findings specified in this paper.

\section{Author Contributions}

Conception and design: Tator, HS Davis. Acquisition of data: HS Davis. Analysis and interpretation of data: Tator, HS Davis, Dufort, Hiploylee. Drafting the article: Tator, HS Davis, Dufort, Hiploylee. Critically revising the article: Tator, HS Davis, Tartaglia, KD Davis, Ebraheem, Hiploylee. Reviewed submitted version of manuscript: Tator, HS Davis, Hiploylee. Approved the final version of the manuscript on behalf of all authors: Tator. Statistical analysis: HS Davis, Dufort. Administrative/technical/ material support: Hiploylee. Study supervision: Tator.

\section{Correspondence}

Charles H. Tator, Toronto Western Hospital, 399 Bathurst St., Rm. 4W-422, Toronto, ON M5T 2S8, Canada. email: charles. tator@uhn.ca. 